\title{
Saberes académicos sobre los accidentes de trabajo en Argentina. 1900-1915
}

\author{
Academic knowledge about work accidents in Argentina. 1900-1915
}

\author{
Pablo Daniel Maddalena \\ pdmaddalena@yahoo.com.ar \\ Instituto de Altos Estudios Sociales. Universidad \\ Nacional de San Martín, Argentina
}

Recepción: 19 Diciembre 2019

Aprobación: 02 Julio 2020

Publicación: 03 Mayo 2021

Cita sugerida: Maddalena, P. D. (2021). Saberes académicos sobre los accidentes de trabajo en Argentina. 1900-1915. Anuario del Instituto de Historia Argentina, 21(1), e137. https://doi.org/10.24215/2314257Xe137

\begin{abstract}
Resumen: El presente artículo indaga en una serie de tesis jurídicas producidas en el mundo académico argentino sobre los mecanismos legales para gestionar los accidentes de trabajo, durante la primera década y media del siglo XX. De esa forma, se registran las distintas doctrinas jurídicas que estuvieron en pugna por oficiar de elemento rector para resolver los desajustes que producían los infortunios laborales. Ello dialoga con la recepción local que tuvieron las ideas generadas en el extranjero y sopesa la injerencia de las agencias estatales a la hora de modelar la ley de accidentes de 1915 .
\end{abstract}

Palabras clave: Accidentes de trabajo, Legislación obrera, Saberes académicos, Doctrina jurídica, Argentina.

Abstract: This article examines a series of legal thesis proposed in the academic field in Argentina concerned about legal mechanisms for managing accidents at work during the first decade and a half of the 20th century. Taking this into consideration, this work makes reference to the different legal doctrines that were at odds to become the leading factors for solving the key issues provoked by the work hardships. This, in turn, is connected with the local reception of the foreign ideas and weighs the influence of the state agencies as entities that shaped the law of accidents issued in 1915.

Keywords: Work accidents, Academic knowledge, Labour legislation, Legal doctrines, Argentina.

Cuando $^{1}$ en 1915 el Parlamento argentino sancionó la ley $\mathrm{n}^{\circ} 9688$ de accidentes de trabajo y enfermedades profesionales, el tema había sido puesto en la agenda del Congreso por los representantes de fuerzas políticas divergentes. Desde 1902, diputados conservadores, socialistas y radicales habían presentado una decena de proyectos legislativos con la intención de regular la gestión de las indemnizaciones que debían recibir los trabajadores que sufrieran una lesión o la muerte producto del ejercicio de su labor. En sincronía con ello, los funcionarios de distintas agencias estatales habían indagado en la temática y aportado fundamentos técnicos acerca de la necesidad de contar con un marco normativo para el arbitraje de la cuestión. Así, desde el Departamento Nacional del Trabajo (DNT) se dio comienzo, a partir del mismo momento de su creación en 1907, a una política de recolección de información estadística sobre los accidentes y de identificación de los avances que la legislación trazaba en distintos 
espacios internacionales. A su vez, algunos médicos higienistas como Augusto Bunge, afincados en el Departamento Nacional de Higiene (DNH), se abocaron a analizar aspectos propios del trabajo industrial en relación con la higiene. Si bien los grados de institucionalización que presentaron tales marcos de producción de saberes respecto de los accidentes de trabajo fueron considerables, el dominio del tema no fue exclusividad de esos espacios.

El presente artículo tiene el objetivo de analizar qué configuraciones adquirieron los saberes constituidos en relación con los accidentes de trabajo en espacios académicos situados más allá de las agencias estatales con atribuciones específicas sobre las cuestiones laborales y médicas, donde los márgenes entre el Estado y la sociedad fueron más difusos (Mitchell, 2015). Ello proporciona a este artículo una utilidad en un doble aspecto. Por un lado, las fuentes analizadas y quienes las produjeron circularon en ámbitos de pertenencia que no podrían diferenciarse como claramente propios de la estatidad o ajenos a ella. Por otro lado, los límites imprecisos entre funciones técnicas estatales y roles externos servirán para discutir en qué medida las prácticas del Estado respondieron a una matriz de acción predefinida (Plotkin y Zimmermann, 2012). Así, la universidad se erige como espacio generador de conocimientos que, para principios de siglo XX, demanda una atención específica, dado que su ligazón con el Estado era más estrecha que los márgenes de autonomía que se irían adquiriendo a partir de la Reforma Universitaria de 1918.

El trabajo promueve una serie de diálogos historiográficos. Por un lado, los estudios de Eduardo Zimmermann (1995) y de Juan Suriano (2000) son centrales para comprender el clima de época en el cual el reformismo de las elites para el primero, y la conflictividad social imperante para el segundo, auspiciaron la atención estatal de una serie de problemáticas que atentaban contra la cohesión social. A su vez, las contribuciones de los trabajos que pusieron el foco en cómo el DNT fue un espacio desde el cual se reclutó información para el conocimiento de los aspectos intrínsecos del mundo laboral ayudan a develar el funcionamiento de los métodos de arbitraje estatal entre patrones y obreros (Lobato y Suriano, 2014). Los estudios que pusieron por centro analítico a la temática de los accidentes de trabajo mostraron la potencialidad que presenta el tema para ser analizado desde diversas perspectivas (Haidar, 2008; Ramacciotti, 2014a). Por otro lado, las investigaciones que recuperaron la historia institucional de las universidades argentinas son piezas insoslayables para comprender el marco académico en el cual se produjeron los conocimientos sobre accidentes laborales a principios de la pasada centuria (Halperín Donghi, 2013 [1962]; Buchbinder, 2005).

En la Argentina, desde fines del siglo XIX, los accidentes de trabajo fueron pensados por académicos y por expertos como una problemática inherente a la modernización del proceso productivo que venía de la mano de una mayor presencia de maquinarias en las fábricas. Esa concepción se tradujo en una discusión entre adherentes a dos teorías jurídicas en disputa. Por un lado, la teoría de la "culpa" enraizada en el Código Civil de 1871, por la cual, para que el trabajador fuera pasible del derecho a indemnización, debía demostrar que el accidente sufrido había sido producto de la responsabilidad de su patrón. Por el otro lado, la doctrina del "riesgo profesional" comenzaba a visibilizar que toda labor tenía un peligro para el obrero que era inherente a la actividad que desarrollaba, y por consiguiente, éste debía ser indemnizado ante un accidente laboral sin necesidad de tener que demostrar la culpabilidad de su empleador. La mayoría de las voces provenientes de los juristas sostuvieron que esa tensión era fruto de la inexistencia de una legislación específica que pudiera trazar los canales y procedimientos para la resolución de los conflictos que se originaban a consecuencia de que un trabajador padeciera un accidente en su trabajo. En este artículo se buscará demostrar que, más de una década antes de la sanción de la ley $n^{\circ} 9688$, los juristas argentinos habían aunado voces en favor de la teoría del "riesgo profesional", en gran medida influidos por la recepción de ideas que sobre los accidentes laborales se habían desarrollado en ámbitos transnacionales.

La investigación se sustentará en la utilización de un corpus documental conformado por una serie de tesis presentadas en el ámbito de la Facultad de Derecho y Ciencias Sociales de la Universidad de Buenos Aires (FDyCS-UBA), y de escritos realizados por quienes también ejercieron expertise en la materia pero no necesariamente se anclaron a una pertinencia institucional. Se entiende que desde esos lugares se generó 
un cúmulo de saberes técnicamente fundados, con ligazón estrecha a un campo profesional o disciplina científica, y que desde estos se buscó la construcción de una legitimidad para colocar al derecho como espacio prominente sobre otras ramas de conocimiento (Morresi y Vommaro, 2011). La trascendencia de la utilización de este material radica en que estas fuentes han pasado casi inadvertidas por la historiografía que se abocó a estudiar el mundo laboral de principios de la vigésima centuria, y cuando llamaron la atención de las investigaciones fueron indagadas desde aristas distintas de las aquí propuestas.

El artículo se inicia con un análisis de las tesis doctorales presentadas desde fines del siglo XIX hasta 1907, las cuales serán utilizadas como herramental empírico que se pondrá en diálogo con aspectos teóricos vinculados con la circulación transnacional de saberes, y con la relación y los límites entre saberes académicos y políticas estatales. A posteriori, se continuará con el abordaje de lo que ocurrió desde 1907, año de creación y puesta en funciones del DNT, ya que esta institución actuó como un espacio aglutinador de los portadores de saberes que antes se producían en el mundo universitario. Por último, se analizarán las voces que nuevamente emergieron desde ámbitos académicos y expertos, desde donde se discutieron los alcances de la ley sancionada en 1915 y las posibilidades de cubrir con ella los vacíos que dejaban no sólo la interpretación del Código Civil sino fundamentalmente las percepciones de los jueces sobre la doctrina jurídica.

\section{DisCUSIONES ACADÉMICAS SOBRE DOCTRINAS JURÍDICAS EN DISPUTA}

En 1898, Ricardo Marcó del Pont ${ }^{2}$ presentó una tesis para optar al grado de Doctor en Jurisprudencia en la FDyCS-UBA, titulada "Responsabilidad en los Accidentes del Trabajo". Allí, el autor se centró en analizar los distintos tipos de responsabilidades que emergían de un accidente: patronal, en su doble sentido de culpa o negligencia; de la víctima del accidente, que al igual que los daños por causa fortuita, al entender de Marcó del Pont no causarían ningún derecho a indemnización en favor del obrero que sufría una lesión en el ejercicio de su tarea (pp. 15-16). En ese análisis, la teoría de la "culpa" aparecía como marco director de la doctrina jurídica que debía regir en los casos de litigios legales por accidentes de trabajo. Según dicha teoría, que se sustentaba en la interpretación del Código Civil, sólo probándose la responsabilidad patronal como causante del accidente el obrero era pasible de indemnización. Esa defensa de la teoría de la "culpa" se hizo en detrimento de la idea que hacía dos décadas había comenzado a circular por Francia, Alemania e Inglaterra, que admitía que la relación laboral en un marco de tecnificación del proceso industrial colocaba a los trabajadores ante un mayor riesgo de sufrir accidentes, y que años más tarde se resumiría en la teoría del "riesgo profesional". 3

La postura asumida por Marcó del Pont, en sincronía con lo que plantea Zimmermann (2013) respecto de cómo la cuestión social incidió en el marco del derecho nacional, estaba representando una mirada clásica del pensamiento jurídico basada en los postulados de un ideario liberal en expansión. Esto favorecía que el derecho se separara de la política, y que adquiriera un espíritu formalista y promoviera una escisión entre el derecho público y el derecho privado. Sin embargo, en esta tesis de 1898 ya había arraigado una incipiente idea de que el pensamiento jurídico debía orientarse a atender una faceta social. Ello fue así en tanto Marcó del Pont indicó que, más que una preocupación jurídica para el gobierno, este tema debía ser una preocupación de tinte social ya que el socialismo y el anarquismo se avecinaban como "peligros" para la estabilidad política (p. 45).

La doctrina de la “culpa” pareció encontrar en Marcó del Pont una de las últimas voces en su defensa. Con el ingreso al nuevo siglo, los cuestionamientos sobre aquella se hicieron cada vez más evidentes. En el primer lustro del 1900, quienes aspiraban a doctorarse en jurisprudencia en el ámbito de Buenos Aires mostraron una mayor sensibilidad ante la situación de los trabajadores accidentados, quizás en vistas de buscar mecanismos para morigerar la conflictividad social creciente. Emilio Hardoy, ${ }^{4}$ que presentó su tesis "La Responsabilidad Civil y los Accidentes de Trabajo" en 1901, no dudó en afirmar que la fábrica era patrimonio del patrón y éste colocaba al obrero ante la máquina, por lo que era responsable de reducir los riesgos y de protegerlo. A 
su vez, planteó que el dueño del establecimiento fabril era quien más se aprovechaba del trabajo obrero, y que ya en la relación causal entre trabajador y patrón estaba implícito que el proceso productivo significaba una agudización de los peligros. La demostración de la culpa, así, pasaba a un plano subsidiario respecto de la mera existencia de la relación laboral. No obstante, el planteo de Hardoy (pp. 27-28) avanzó hasta proponer que ya no debía ser el obrero quien demostrara la responsabilidad de su patrón por el daño sufrido, sino el empleador dar cuenta de que el accidente se había producido por causas ajenas a sus posibilidades de evitarlo; en tal caso, el accidente quedaba identificado como fortuito o como responsabilidad de la víctima, y se eximía al patrón de la indemnización.

Un punto en común de las tesis que se presentaron en los años de pasaje del siglo XIX al XX fue la recurrencia a las producciones de saberes que se realizaban en otras naciones. Hardoy citó a los juristas franceses, representados principalmente por la figura de Raymond Saleilles y su trabajo de 1897 Les accidents de travail et la resposabilité civile, para mostrar que la teoría del "riesgo profesional" recibía adhesiones argumentativas cada vez más firmes. Sin embargo, Hardoy también utilizó a Saleilles en otro sentido más favorable a sus intenciones: ${ }^{5}$ estableciendo un diálogo entre el Código Civil argentino, el Código Napoleónico y el derecho romano, propuso que la salida al debate acerca de la "culpa" y "el riesgo profesional" debía ser saldada con una reinterpretación del artículo 1109 del Código Civil. ${ }^{6}$ Esto era un obstáculo para la renovación jurídica pretendida por Hardoy, quien al no plantear la necesidad de una legislación específica sustentada en la doctrina del "riesgo profesional" para los casos de accidentes, no podía avanzar más que en la inversión de la prueba. Según él, debía ser el empleador quien diera cuenta de su inocencia en relación con la lesión padecida por el obrero a su cargo. Tal perspectiva volvía la discusión a manos de los jueces, quienes, rigiéndose por la interpretación del Código Vélez Sarsfield, tenían un margen cierto de maniobra para inclinarse por cualquiera de las teorías jurídicas en pugna.

En un contexto de redefinición de las relaciones entre el debate académico y el público, las tesis presentadas por Domingo Salvatierra y Eudoro Gorlero Pizarro, también en el ámbito de la UBA, pero durante los años 1905 y 1907 respectivamente, tuvieron una finalidad diferente de las producidas años atrás. Mientras para Marcó del Pont (1898, p. 10) y para Hardoy (1901, p. 55), sus escritos habían sido realizados para cumplir con una pauta reglamentaria de la Facultad de Derecho, Salvatierra y Gorlero Pizarro (1907) se mostraron más proclives a generar un debate jurídico sobre el tema de los accidentes laborales. Ese viraje tuvo relación con las discusiones que recaían sobre el alto contenido de profesionalismo de las universidades, ante lo cual se promovían investigaciones científicas que fomentasen el sentido cultural de la formación y promoviesen personal a los ámbitos políticos (Buchbinder, 2005, pp. 65-67).

La presentación de los primeros proyectos legislativos con la intención de regular los accidentes modificó el sentido del quehacer universitario. En 1902, dos diputados por la Capital, Belisario Roldán (hijo) y Marco Avellaneda, presentaron un proyecto en el Parlamento. Dos años más tarde, en el pretendido Código del Trabajo dirigido por Joaquín V. González, los accidentes laborales ocuparon un espacio no desdeñable. Salvatierra (1905, pp. 44-45) se centró en debatir con los dos proyectos legislativos: sobre el de Roldán y Avellaneda, del cual rescató que ya se encontraba presente la teoría del “riesgo profesional”, mencionó que era prácticamente una transcripción literal de la ley española sancionada en 1900. Más detenidamente, Salvatierra (1905, p. 59) se dedicó a argumentar respecto de las modificaciones que desde el punto de vista de la técnica jurídica era necesario realizar al proyecto de González: no sólo sugería cambios al orden en que se presentaban los artículos, sino que criticó al Ministro de Justicia e Instrucción Pública por el hecho de disminuir la responsabilidad empresarial en los casos de accidentes por casos fortuitos, al igual que por considerar el embarazo como una enfermedad profesional. Salvatierra respaldó sus críticas utilizando el texto del jurista francés, y Presidente del Tribunal Civil de Viena, Adrien Sachet, quien en 1900 había publicado Traité théorique et pratique de la législation sur les accidents du Travail, con el que efectuó un análisis de la legislación y de la doctrina aplicada a las intervenciones jurídicas que se producían en Europa. Sachet fue una remisión ineluctable para la jurisprudencia nativa. Sus trabajos se estructuraron en la cita a dos eminentes 
jurisconsultos -Sauzet en Francia y Sainctelette en Bélgica- que en 1884 ya habían fallado en favor de la responsabilidad patronal, y también a Saleilles, quien se erigía como la referencia que había dado un paso adelante en la defensa de la teoría del "riesgo profesional".

Tanto Salvatierra como Gorlero Pizarro mostraron una mayor dedicación que las tesis anteriores para recoger las experiencias europeas en materia legislativa sobre accidentes. Así, los análisis que refirieron a accidentes de trabajo y que se presentaron a mediados de la primera década del siglo XX mostraron que el marco de las naciones europeas era una fuente de provisión de ideas sobre las que se sustentaban las propuestas materializadas en el país. Los tratados de los juristas franceses fueron ampliados con la referencia a las actas de los congresos internacionales sobre accidentes que venían organizándose en Europa desde 1891 (Ramacciotti, 2014b). También, los viajes que hombres vinculados al mundo jurídico efectuaron hacia el otro lado del Atlántico fueron un insumo para la renovación de las ideas sobre los riesgos laborales. Tal fue el caso de Marco Avellaneda, quien antes de asumir la presidencia del DNT en 1909 realizó una larga visita a instituciones laborales, entre las que se destacaron el Museo Social de Paris y el Instituto de Reformas Sociales de Madrid (Suriano, 2015).

Lo que se observa en estas primeras producciones de saberes sobre accidentes de trabajo, más que una participación activa en ámbitos internacionales de circulación de ideas, es una importación de las nociones que se estaban produciendo en Europa, y que fueron tomadas como legitimadoras de los basamentos teóricos esgrimidos por académicos y expertos, en torno a 1900. Esto entra en diálogo con lo propuesto por Yves Dezalay y Bryant Garth (2002), en tanto los marcos legislativos han vehiculizado relaciones de dominación colonial que mediante viajes y experiencias educativas de las elites se reflejaron en la invocación de lo que para el período analizado acontecía en Europa. El lugar protagónico que les cupo a Francia, Inglaterra y Alemania como referencias de las producciones legislativas en caso de accidentes fue completado por aportes extraídos de otros territorios; por ejemplo, los métodos de estudio basados en la legislación comparada arraigados en los funcionarios del DNT, luego de 1907, llevaron la mirada a lo que ocurría en países como Suecia, Luxemburgo, Noruega, Estados Unidos, Nueva Zelanda y Australia.

En los primeros años del siglo XX el influjo de información suministrada por el mundo académico a los ámbitos de poder legislativo y jurídico no fue significativo. Resulta plausible inferir que existieron redes de sociabilidad por las cuales circularon los saberes académicos en dirección al plano político. Tal fue el caso de Marco Avellaneda, coautor del primer proyecto para legislar accidentes presentado en el Parlamento, que por su pertenencia al cuerpo docente titular de la FDyCS-UBA circundó ámbitos que le ofrecieron un punto de encuentro con las tesis en Jurisprudencia a las cuales se hizo referencia precedentemente. Ahora bien, esas redes de sociabilidad entre la academia y los poderes públicos tenían lugar desde los orígenes de la vida universitaria. Pero, como se verá en el apartado siguiente, el rol del DNT, y su aparición en el seno del Estado comoárea de intervención con especificidad sobre el mundo laboral, demandaron un conocimiento más cabal de la temática y oficiaron como receptor de jóvenes figuras provenientes del mundo jurídico.

Más aún, los registros de referencias que los integrantes del poder judicial realizaron sobre las producciones provenientes de los recientemente graduados en derecho se circunscribieron a la figura de Ernesto Quesada en su doble función de juez en el fuero civil y de profesor de la cátedra de Economía Política en la Facultad de Ciencias Jurídicas y Sociales de la Universidad Nacional de La Plata (FCJyS-UNLP). Quesada fue uno de los primeros jueces en sentenciar un caso de accidentes de trabajo sustentándose en la doctrina del "riesgo profesional”, aunque sin explicitarla como tal. ${ }^{7}$ Ello ocurrió en 1903 y se debía fundamentalmente a la recepción de las ideas de Raymond Saleilles, que habían cautivado al jurista argentino en su visita a la Facultad de Derecho de París (Aragoneses, 2015). No obstante, la mirada de Quesada no se dirigía únicamente a las producciones de conocimiento foráneas y ello quedaba de manifiesto cuando, al inaugurar el seminario de Economía Política que en el año 1907 dictó en la FCJyS-UNLP, citó entre otras producciones jurídicas nacionales la tesis de Domingo Salvatierra. ${ }^{8}$ Ello puede ser leído como parte de una estrategia del magistrado 
para dar sustento científico a sus posicionamientos doctrinarios, pero sobre todas las cosas es una muestra de que las redes por las cuales se sociabilizaba el conocimiento comenzaban a tejerse.

\section{LA BÚSQUEDA DE UNA APLICACIÓN PRÁCTICA DE LA TEORÍA JURÍDICA A TRAVÉS DE LAS AGENCIAS ESTATALES}

Desde mediados de la primera década del siglo XX, las profesiones jurídicas fueron modelándose de acuerdo con las demandas estatales, que a su vez retroalimentaban el proceso de institucionalización de dicha profesión (Frederic, Graciano y Soprano, 2010). Puede afirmarse que esto se vio materializado en la estrecha relación de la profesión jurídica con la intervención estatal sobre el mundo laboral, no sólo porque gran parte de las personalidades que para la época ocuparon los cargos políticos en el Ministerio del Interior eran profesores de la FDyCS-UBA -Joaquín González, Manuel Montes de Oca, Marco Avellaneda-, sino fundamentalmente por la participación de los abogados en los momentos de génesis del DNT. Allí, José Matienzo como primer presidente de la institución, durante los dos aos en que perduró en su cargo, reclutó a Alejandro Unsain, Alejandro Ruzo, Federico Figueroa, Pablo Storni, todos recientemente graduados en derecho (Zimmermann, 1995).

Si puede señalarse que hasta 1907 las producciones de expertos y académicos sobre el tema de accidentes encontraron poco eco en esferas donde sus posiciones teóricas pudieran llevarse a la práctica, la creación y puesta en funciones del DNT modificó esa lógica. En cierta medida, ello se debió a que quienes monopolizaron las voces sobre las necesidades de una legislación obrera -dentro de la cual los infortunios ocurridos en el trabajo mostraron marcado protagonismo- tuvieron destacados vínculos con la agencia laboral. Sin embargo, en este apartado se registran las producciones de figuras que, si bien eran parte del funcionariado del DNT, emitieron opiniones sobre accidentes a través de sus tesis para doctorarse en jurisprudencia o meramente como especialistas en derecho, en espacios de circulación desde donde fue más difusa su dependencia de su ámbito laboral. La importancia de recoger tales voces radica en que ayudan a vislumbrar que las opiniones de los juristas del DNT, aun cuando se esgrimían por fuera de la entidad y podían dispensar mayor grado de autonomía, estuvieron en sintonía con los puntos de vista que se difundían oficialmente. Ello así, es plausible sostener que los canales de comunicación entre la academia y los espacios estatales alcanzaban un importante grado de fluidez.

En 1906, cuando Alejandro Ruzo ${ }^{9}$ presentó su tesis “Legislación obrera” para optar al grado de doctor en jurisprudencia por la UBA, tanto José Matienzo como Ernesto Quesada eran académicos titulares de la FDyCS-UBA. Esto pudo haber beneficiado un diálogo recíproco entre quien finalizaba sus estudios universitarios y la figura ya consagrada en el mundo judicial de Quesada, así como con la de Matienzo, también referente del mundo académico y luego presidente del DNT. Ruzo (1906) inició su presentación con una defensa sostenida de lo imperioso de una mediación del Estado en las relaciones entre capital y trabajo, alejada de las medidas coercitivas con que se trataba a los trabajadores, en una búsqueda por aplacar la conflictividad social. Al igual que Storni ${ }^{10}$ y los primeros trabajos de Unsain, Ruzo acercó un capitulado de cada uno de los temas en los que le interesaba ahondar, entre los cuales se encontraba el de los accidentes de trabajo. Allí compartía preocupaciones con sus colegas. ¿Qué se entendía por accidente laboral? ¿Era mejor el sistema de seguro obligatorio o el facultativo? ¿ ¿Debían los seguros estar en manos de compañías privadas o del Estado? ¿Cómo debían establecerse los montos de las indemnizaciones? ¿Qué se entendía por patrón desde la óptica de los proyectos de ley?

Que esos interrogantes rigieran la exposición de Ruzo, y fueran también planteados por otras personalidades públicas a lo largo de la década subsiguiente, da un indicio de que para estos funcionarios la recurrencia al Código Civil como marco de referencia para resolver litigios por casos de accidentes ofrecía limitaciones prácticas y, en consecuencia, se precisaba una ley específica para normarlos. Ello encontraba 
traducción a partir de la manifestación de Ruzo, quien sostuvo que la falta de una legislación específica daba a los jueces un amplio margen de interpretación de los Códigos vigentes, en el que la jurisprudencia pasaba a ser como "una veleta que está a la acción del viento" (Ruzo, 1906, p. 177).

$\mathrm{Ni}$ los saberes que se acumulaban sobre la cuestión de los accidentes ni los cambios en la doctrina jurídica podían asegurar una resolución si no justa, al menos uniforme, en los casos de lesiones sufridas por los obreros en el lugar de trabajo, por más que ciertas prácticas mostraran una paulatina mejora de la posición de la clase trabajadora frente al desasosiego de tiempos anteriores. Pero el convencimiento de que la sanción parlamentaria de la ley de accidentes subsanaría los inconvenientes con los que se enfrentaba la justicia ante la ausencia de una legislación específica no era compartido ni por Storni ni por Unsain, en tanto interpretaban que los mecanismos para garantizar su cumplimiento eran deficitarios. Storni fue crítico del esquivo rol que el DNT adquiría como policía del trabajo. Para él, la función de vigilancia debía ser un central atributo de la agencia laboral y sólo ella podía garantizar el cumplimiento de las disposiciones legislativas. Recién con la ley $\mathrm{n}^{\circ} 8999$ de 1912, que determinaba la organización del DNT, se creó junto a las secciones de Estadística y Legislativa, la de Inspección, casualmente a cargo de Storni.

Las críticas de Storni, quien era miembro del DNT desde sus orígenes, fueron parte de las tensiones que se suscitaban entre los funcionarios del DNT sobre la cuestión del rol de la institución en materia de inspección y, por carecer de tales atribuciones, respecto de la pertinencia de los proyectos legislativos que generaba la entidad. Esto demuestra que no sólo es necesario descomponer el Estado en sus agencias, muchas veces como parte de elementos con perspectivas divergentes que complementan o compiten respecto de las facultades para dirimir aspectos de ciertas temáticas, sino que a su vez dentro de cada oficina puede haber voces en pugna que hacen imperioso inmiscuirse en las trayectorias y opiniones de los funcionarios que las encarnan.

Alejandro Unsain, ${ }^{12}$ quien en 1915 inició una recopilación de la legislación laboral que tituló Manual de la Legislación Obrera y que iría actualizando hasta 1952, año de su muerte, quizás fue quien más conocimiento práctico logró sobre el tema de accidentes de trabajo. Y ello se debió a que fue un férreo defensor de la idea por la cual la legislación del trabajo era una legislación específica que debía llenar el vacío dejado por los Códigos Civil y Comercial. Por ello, fue explícito cuando comprendió que las sentencias del juzgado de Quesada basadas en el "riesgo profesional" eran una excepción a la regla, argumento que le sirvió para discutir con Bialet Massé, quien en 1904 había sostenido que el Código Civil permitía determinar la responsabilidad en casos de accidentes. Unsain presentó algunas interesantes conclusiones durante sus estudios. A diferencia de sus predecesores, analizó los procesos productivos para llegar a la premisa de que los accidentes se daban tanto en los lugares donde existía maquinismo moderno como donde había métodos de producción más tradicionales, e incluso en el mundo agrario (Unsain, 1915). También como rasgo notable, Unsain hizo hincapié en lo que contemporáneamente se conoce como las condiciones de seguridad e higiene en el trabajo; para él, la prevención era un valor fundamental para atacar los accidentes de raíz y no atenderlos desde una mirada correctiva que se traducía en una indemnización.

Si durante la primera mitad de la década inicial del siglo XX la referencia internacional sobre cómo se trataban los casos de accidentes de trabajo había sido el mundo europeo, Unsain, al igual que Ruzo y Storni casi una década antes, prestaban mayor atención a lo que ocurría en la región. En este sentido, si bien la historiografía que se ocupó sobre la circulación transnacional de ideas en materia de accidentes indica que un nuevo escenario se abrió luego de la primera posguerra, cuando los diálogos con los países de la región sirvieron de marco de referencia para el tema, y entidades como la Organización Internacional del Trabajo ocuparon espacios de discusión que morigeraban las influencias europeas (Ramacciotti, 2014b), estos tres autores mostraron un precedente al respecto. Estuvieron atentos a las opiniones ${ }^{13}$ y a la legislación que se producía en Latinoamérica, fundamentalmente a la legislación uruguaya que limitaba la jornada máxima de trabajo y a la ley de accidentes de Perú promulgada en 1911, aunque también repararon en lo que ocurría en Chile y en Cuba. 
El trabajo que Unsain publicó en 1915 precedió en pocos meses a la sanción de la ley de accidentes, aunque eso no fue un obstáculo para su mirada perspicaz sobre los interrogantes que aún restaba dilucidar para que la norma tuviera un efecto certero. En ese plano, las preocupaciones de Unsain se dirimieron en dos sentidos. Por un lado, en determinar los niveles de autonomías provinciales y también municipales para dictar normas reglamentarias que regularan los casos de accidentes. Por el otro, en estipular las formas de constitución de los seguros en los casos en que estos fueran facultativos u obligatorios, privados o estatales.

En 1916, Unsain volvió a publicar un trabajo, Leyes Obreras, que consistió también en una recopilación de la legislación laboral sancionada y de sus decretos reglamentarios, acompañada por comentarios sobre los alcances y limitaciones que presentaba para una efectiva aplicabilidad. Una vez más, su propósito era demostrar que el conjunto de leyes obreras dictadas podía ser parte de un proceso de constitución de un Código Obrero, en sintonía con lo que más de una década antes había pensado Joaquín González (Unsain, 1916, p. 6). En lo que a accidentes de trabajo correspondía, Unsain fue un defensor de lo que significó la sanción de la ley n ${ }^{\circ}$ 9688: para él, "la ley de indemnización en los casos de accidentes de trabajo señala uno de los puntos de más culminante interés en el sistema argentino de la previsión social” (Unsain, 1916, pp. 12-13). Sin embargo, Unsain también advirtió que la ley era perfectible e identificó una serie de vacíos que no cubría. Ello lo llevó a realizar un estudio específico en 1917, que tituló Accidentes de Trabajo y en el que planteó los inconvenientes prácticos que presentaba la ley (Unsain, 1917).

Es válido enfatizar que la pertenencia al ámbito público de figuras como Ruzo, Storni y Unsain, y dentro de ese espacio con los engranajes que estaban activándose para intervenir cada vez más marcadamente en la regulación de los vínculos entre el capital y el trabajo, fueron significativos a la hora de modelar sus posicionamientos intelectuales. No obstante, los enfoques de estos tres personajes encontraron una serie de puntos en común, que a su vez los diferenciaron de las tesis académicas precedentes. En primer lugar, Ruzo, Storni y Unsain compartieron una preocupación con importantes sectores de la elite política e intelectual de la época y que se identificaba en los interrogantes emparentados con cómo definir, entender y atender a la cuestión social, que enraizaron en la cuestión obrera, razón por la que se enfocaron en el estudio del mundo laboral y de las formas de regularlo. En segundo lugar, los tres identificaron que el infructuoso destino que le había tocado al proyecto de Ley Nacional del Trabajo de Joaquín González de 1904 dejaba un vacío en materia legislativa que debía ser cubierto, si no con un Código Laboral, con un conjunto de leyes que, aunque sancionadas en forma independiente, actuaran sinérgicamente con el objetivo de arbitrar las relaciones del trabajo. En tercer lugar, las opiniones de estos tres juristas no se quedaron en una actitud analítica o descriptiva del contexto, sino que tuvieron un sentido de crítica propositiva en el afán de perfeccionar los saberes sobre el mundo obrero; para ello, no sólo entendieron el conocimiento como parte de una trayectoria que debía ser acumulativa, sino que también utilizaron la energía de sus plumas para señalar que sus producciones se realizaban en un momento en que la práctica debía poner a prueba las teorizaciones. Por último, tanto Ruzo como Unsain, y en menor medida Storni, se destacaron en su capacidad de estudiar lo que acontecía con las relaciones laborales en el extranjero, como parte de una práctica en boga para la época, la legislación comparada, pero no por ello dejó de estar en el centro de sus planteos la opinión tácita en favor de evitar transcripciones textuales de las leyes foráneas y de adaptarlas a las necesidades que imponían las condiciones de producción en la Argentina.

Escrutar en los enfoques de Ruzo, Storni y Unsain proporciona una entrada diagonal al pensamiento de estos protagonistas y sus actuaciones por fuera de su pertenencia institucional. A la vez, enriquece el análisis ya que posibilita un distanciamiento de la monocorde voz emergente de los órganos de difusión estatales. $\mathrm{Si}$, como se mostró en el primer apartado de este artículo, el mundo académico permitió una proliferación variopinta de miradas sobre los accidentes laborales, sustentada en una matriz más bien teórica que práctica, la relación de Ruzo, Storni y Unsain con el DNT les permitió pensar en la necesidad imperiosa de poner a prueba por medio de una legislación específica lo que sostenían desde el punto de vista teórico, y en ese 
sentido intentaron que sus opiniones presionaran a sus niveles políticos superiores con facultades ejecutivas o parlamentarias en pos de la sanción de la ley.

De esta manera, es plausible sostener que más de una década antes de la sanción de la ley $n^{\circ} 9688$ los juristas argentinos habían aunado voces en favor de la teoría del "riesgo profesional", en gran medida influidos por la recepción de ideas que sobre los accidentes laborales se desarrollaron en ámbitos transnacionales. Si bien la historiografía ha dado cuenta de cómo el poder judicial actuó como árbitro de las relaciones laborales previamente a la intervención legislativa, centrándose para ello en el rol de los jueces (Schjolden, 2009), se considera que las discusiones teóricas en materia de derecho no fueron suficientemente atendidas y ofrecen a la investigación sobre el tema una puerta de entrada que complementa las producciones de saberes que emanaron desde las agencias estatales. Y si esos espacios un tanto difusos para pensar los límites entre la estatidad y la sociedad civil arrojan luz sobre el camino por el cual la legislación y la práctica jurídica entraron en vigencia, resulta conveniente poner el foco de la mirada más allá de la centralidad que pudiera otorgarse al DNT en el diseño de la política laboral (Lobato y Suriano, 2014).

\section{LA LEY DE ACCIDENTES DE TRABAJO: ENTRE MIRADAS DE BENEPLÁCITO, CUESTIONAMIENTOS E INDIFERENCIAS}

Desde 1915, momento de sanción de la ley de accidentes, las voces que opinaron sobre los alcances y limitaciones de la nueva legislación ya no estuvieron monopolizadas por expertos que tenían una relación con el DNT. Una vez más, el mundo académico actuó como referencia para el tema, lo cual pudo deberse a una práctica que se suscitaba entre las tesis universitarias en derecho, por la cual, ante una nueva ley promulgada, se analizaba su contenido. Sin embargo, dentro de estas voces hubo algunas que siguieron preguntándose por la conveniencia de avanzar sobre la doctrina del "riesgo profesional", la responsabilidad en casos de accidentes y las características de los seguros, como si la presencia de la ley $n^{\circ} 9688$ no hubiera marcado un hito al respecto. Otros planteos se hicieron desde una crítica a las falencias que desde la óptica jurídica planteaba la ley, mientras que pocas expresiones se mostraron satisfechas por el nuevo marco legal. Si las voces que se alzaron para opinar sobre la novel legislación fueron polifónicas, a partir de esas tensiones cabe preguntarse qué nuevo escenario -si es que existió- vino a plantear la ley de accidentes como marco legislativo sobre el cual tuvieron que actuar los jueces.

Cuando Unsain publicó Accidentes del Trabajo. Exposición y comentarios a la Ley $N^{\circ} 9.688$ y sus decretos reglamentarios, en 1917, dio muestras de un cúmulo de imprecisiones que contenía la legislación. El carácter explicativo del texto dejaba entrever que la ley de accidentes no alcanzaba, por sí sola ni por el marco de aplicación que otorgaba su reglamento, para dar cobertura a una problemática tan compleja. Cada artículo del reglamento era seguido de un comentario que buscaba arrojar luz sobre lo que la legislación no dejaba ver. Que un perfil técnico como el de Unsain en su rol de funcionario del DNT, pero con un respaldo que le daba su pertenencia al campo académico del derecho, se esforzara por explicar el sentido de la ley puede verse como un intento por sentar las bases sobre las cuales la justicia debía encaminarse a la hora de interpretar los alcances de la recientemente sancionada medida. Ello expresaría parte de las tensiones existentes entre los poderes que habitaban en el Ejecutivo, el Legislativo y el Judicial por acaparar los márgenes que la legislación y su aplicación no llenaban de sentido.

En su trabajo de 1917, quizás el análisis más exhaustivo de la ley de accidentes que dejó la época, Unsain destacó que el terreno ya estaba preparado para la sanción de una legislación que versara sobre el tema, en tanto ciertas cuestiones determinadas por la ley n ${ }^{\circ} 9688$ estaban ya implementadas en la práctica. El autor sostuvo que la ley surgió espontáneamente, producto de acuerdos entre los actores del mundo del trabajo. Y una importante contribución a ello fue la evidencia estadística producida por el DNT, en la que se demostró la proliferación de los accidentes, el aumento de las pólizas de seguro emitidas y, fundamentalmente, la existencia de prácticas jurídicas que se anticipaban al marco legal que la norma vendría a regular. 
En Accidentes del Trabajo Unsain dejó entrever la superposición legislativa que existía en la materia. Ello generaba que el trabajador accidentado pudiera recurrir a los instrumentos dispuestos tanto por la ley $\mathrm{n}^{\circ} 9688$ o por el Código Civil. A esta falta de unicidad legislativa como herramienta para resolver los litigios en casos de accidentes laborales, se añadía la existencia de la ley n ${ }^{\circ} 9085$ sancionada en 1913 como mecanismo regulatorio para indemnizar a los obreros que habían sido víctimas de una explosión en talleres estatales cercanos al Riachuelo (Unsain, 1917). Esos intersticios a la hora de identificar cuál era la ley que debía utilizarse en cada caso eran una muestra más de la perfectibilidad que requería la normativa.

A diferencia de sus trabajos anteriores, Unsain recaló en una serie de imperfecciones que tenía la ley de accidentes, las cuales podían ser interpretadas como recomendaciones para una próxima modificación legislativa. Retomó una idea que había ya deslizado y sobre la que también había reparado Augusto Bunge, cuando a seis meses de sancionada la ley $n^{\circ} 9688$ propuso cambios en la norma a causa de que la indemnización se realizaba en forma de renta y no de capital. Para Unsain (1917), el sistema de pago en forma de renta era una falencia central en la ley, fundamentalmente por el bajo interés que los montos depositados en las cajas de inversiones producían. La crítica de Unsain traía un trasfondo: la especulación de las cajas de inversiones, que a su criterio actuaban como si fueran banqueros. Así y todo, el autor de Accidentes del Trabajo entendió que la ley era el producto más equitativo que podía lograrse en tanto protegía a empleados y a obreros por igual. Los comentarios positivos de Unsain sobre la ley de accidentes laborales estuvieron siempre ligados a que la legislación ofrecía un marco de previsibilidad, siempre bien ponderada por empresarios que buscaban minimizar riesgos y que encontraba traducción cuando se establecían montos máximos para las indemnizaciones. Unsain también veía con buenos ojos la forma en que la ley inducía a los industriales a la contratación de un seguro que los eximiera del pago de un resarcimiento no previsto.

Las opiniones de Unsain eran el punto de vista de un representante técnico con trayectoria en el DNT aunque con un entronque jurídico a raíz de su formación en derecho. A su doble recorrido formativo se añadía su prolongada actividad ligada al mundo del trabajo. No obstante ello, su opinión en la materia no logró actuar como referencia única para las voces que se esgrimían desde otros ámbitos, y mucho menos ser monopólica. El tema de los accidentes de trabajo volvió a recibir atención en el marco académico a partir de las tesis que se elaboraron en diversas facultades de derecho del país.

Algunos trabajos, como el de Luis Bonaparte realizado en 1917 en la Universidad de Santa Fe, recopilaron los antecedentes de la aplicación del Código Civil como fórmula para resolver los litigios en casos de accidente. Para su análisis, Bonaparte trazó un paralelo con lo que ocurrió en Francia en los momentos previos a 1898, año de la sanción de la legislación sobre accidentes; a partir de ello encontró que la jurisprudencia francesa ya había evolucionado en favor de la doctrina del "riesgo profesional”, aun antes de la promulgación legislativa, lo que también había ocurrido en la Argentina. El análisis de Bonaparte demostró cómo, por medio de diversos fallos, jueces como Ernesto Quesada en 1903 y en 1905, Agustín Urdinarrain en 1909 y Jorge de la Torre en el mismo año, estaban sentando jurisprudencia favorable a resolver los litigios con base en la doctrina del "riesgo profesional" (Bonaparte, 1917).

Otras tesis, como las producidas por Rafael Bielsa, Gonzalo Figueroa Gacitúa, Pedro Pelento, Juan Carlos Díaz y Juan Chazarreta, todas en la Universidad de Buenos Aires en 1918, volvieron a tomar por centro de la discusión el concepto de la culpa. Significativamente, las cinco tesis se titularon La culpa en materia de accidentes del trabajo, y aseveraron la necesidad de precisar el alcance del concepto. En tales estudios se trazó el recorrido de cómo fue evolucionando la teoría jurídica en el extranjero, desde su basamento en la culpa según el derecho romano, hasta el "riesgo profesional" que rigió a la ley $\mathrm{n}^{\circ} 9688$. Los análisis aunaron voces críticas por la falta de definiciones que la legislación y su reglamentación habían aportado sobre categorías trascendentales para una correcta aplicación práctica de la norma. Ello era así no sólo porque no se especificaba qué comprendía la idea de accidente de trabajo (Figueroa Gacitúa, 1918), sino también porque el concepto de la culpa no estaba claramente determinado. Las tesis de Bielsa (1919) y de Díaz (1918) fueron aún más allá, porque volvieron a reparar en la idea de la culpa grave de la víctima que eximía al 
patrón de la responsabilidad indemnizatoria que le imponía la ley. Si a tres años de promulgada la legislación sobre accidentes las miradas recaían nuevamente en la necesidad de determinar por culpa de quién se había producido el infortunio, se imponía una pregunta: ‘hasta dónde la doctrina del "riesgo profesional" había desplazado al principio de la culpa como forma de discernir si un obrero que sufría una lesión en el ejercicio de su labor debía ser resarcido económicamente?

Las cinco tesis citadas relevaron con mayor dedicación las discusiones que se producían en el extranjero, donde los juristas franceses llevaban la delantera. Sin embargo, la recurrencia a lo que sucedía en el ámbito nacional siguió predominando en al menos tres planos. Por un lado, las producciones de Alejandro Unsain marcaron una referencia obligada para los facultativos, quienes en no pocas ocasiones también registraron las publicaciones que realizaban los funcionarios del DNT en su Boletín. Por el otro, los fallos de la justicia argentina sobre los accidentes sirvieron como ejemplos para mostrar cómo la evolución de la doctrina jurídica se implementaba en la práctica. En tercer término, la ley n ${ }^{\circ}$ 9085, que en 1913 se había sancionado con el objeto de indemnizar a los trabajadores estatales accidentados a orillas del Riachuelo, era reconocida como el antecedente directo de la ley $n^{\circ} 9688$ que venía a ampliar su alcance.

Más allá de las críticas, recepciones airosas (Pelento, 1918) ${ }^{14}$ o indiferencias (Figueroa Gacitúa, 1918) ${ }^{15}$ que suscitó la ley de accidentes del trabajo y enfermedades profesionales del año 1915, la mirada que los tesistas en derecho pusieron sobre los fallos que se habían producido frente a litigios por accidentes laborales arrojaron luz sobre lo que ocurría en los años que precedieron a la sanción de la norma. Federico Gacitúa dejó entrever que, más allá del camino que la jurisprudencia trazaba hacia el "riesgo profesional" como principio para resolver los casos de accidentes, los jueces contaban aún con amplio margen de libertad para decidir acerca de si cabía la responsabilidad indemnizatoria sobre el patrón. Juan Chazarreta fue más allá a la hora de evaluar la coherencia con la cual los jueces resolvían los litigios en casos de accidentes con prelación a la ley de 1915, y si bien comprendió que una interpretación extensiva del Código Civil hubiera bastado para arbitrar sobre el tema, también denunció que "la falta de una ley especifica hizo que la jurisprudencia de nuestro pais fuera vacilante, tornadiza, contradictoria y arbitraria" (Chazarreta, p. 46).

A partir de tales interpretaciones, cabe preguntarse hasta qué punto la ley de accidentes laborales podía ser considerada como un parteaguas en materia de legislación laboral y de previsión social. Cierto resulta que las tesis hicieron hincapié en que la evolución jurídica respondía a los cambios y problemáticas que traía aparejada la cuestión social, pero no menos revelador aparece que la jurisprudencia anterior a 1915 aún contenía posturas heterogéneas respecto de cómo resolver los conflictos entre el capital y el trabajo en caso de accidentes. El principio del "riesgo profesional" se imponía como herramienta para la argumentación de la justicia argentina, en espejo de lo que ocurría en los países que habían iniciado el camino de legislar los infortunios del trabajo, y la ley $n^{\circ} 9688$ puede ser vista como un intento más por afirmar ese precepto rector para los jueces. Sin embargo, las imprecisiones que la ley aún contenía, señaladas no sólo por las tesis presentadas en la FDyCS-UBA sino también en los planteos de reforma de la norma que habían alcanzado el Parlamento de la mano de Augusto Bunge en 1916 y de Francisco Beiró en 1918, dejaban intersticios para que los jueces tuvieran la facultad de interpretar los alcances y limitaciones de la legislación. La ley se mostraba menos inflexible en promover cánones de previsión a los patrones, quienes, por ejemplo, sabían de qué manera y hasta qué monto debían indemnizar a los obreros bajo su responsabilidad. El seguro en caso de accidentes, facultativo según la legislación, era atacado por las opiniones avezadas en derecho, que sostenían que lograr su obligatoriedad era reducir al mínimo los riesgos de los representantes del capital.

\section{A MODO DE BALANCE}

El derrotero que siguió la relación entre la producción de saberes en el ámbito académico y las opiniones de los técnicos que buscaban un campo de aplicación de conocimiento en las agencias estatales fue cambiando con el tiempo. Como se observó, en un primer momento la Universidad fue un espacio de 
seguimiento de las transformaciones que avizoraba la doctrina jurídica en los países que fueron referencia en la materia, con Francia como protagonista. La academia permaneció un tanto al margen de la influencia que recibieron las esferas de los poderes Ejecutivo y Legislativo para promover la sanción de una ley que se sustentara en los conocimientos alcanzados en el espacio universitario. No obstante, los años medios de la primera década del siglo XX empezaron a mostrar que los vínculos entre lo que dictaminaban los poderes públicos y los saberes académicos se fueron estrechando. Con la creación del DNT en 1907, las relaciones entre la justicia, el conocimiento académico y los técnicos que buscaban su aplicación desde funciones medias en la esfera estatal se hicieron más fluidas, y las redes de sociabilidad se tejieron sobre lazos más firmes que mostraron que las ideas fueron circulando con cierta holgura por esos espacios. Sancionada la ley $\mathrm{n}^{\circ}$ 9688, una vez más la academia volvió a analizar los alcances de la norma y su reglamentación, en algunas ocasiones desconociendo el marco doctrinario sobre el cual la nueva legislación se cimentaba.

Si bien resulta cierto que observar las profesiones jurídicas a través del cristal de las agencias estatales, como el caso del DNT, permite identificar momentos en los que se catalizan las relaciones entre ambos campos de producción de conocimiento, ello no debe ser óbice para aproximar una mirada a los prolegómenos de ese vínculo. Las producciones de saberes académicos y expertos registradas en este artículo intentan mostrar la importancia no sólo de entender al Estado desde una perspectiva desagregada en las distintas voces que muchas veces con sentidos disímiles se modulan desde sus agencias (Migdal, 2001), ${ }^{16}$ sino también de construir lo que acontecía en ámbitos donde la separación entre Estado y sociedad presenta márgenes más difusos. En busca de una definición, podemos ilustrar estos márgenes a partir de la metáfora propuesta por Veena Das y Deborah Poole (2008, p. 29), "no tanto como sitio que queda por fuera del Estado, sino más bien como rios que fluyen al interior y a través de su cuerpo". Quizás el ejercicio empírico de interpelar los documentos analizados a partir de esta perspectiva sea menos cómodo que el de establecer ligazones entre los funcionarios que forman parte del DNT y la política pública sancionada en la ley de accidentes de trabajo de 1915. Detenernos en estas fronteras permeables entre lo que acontece en las agencias estatales con especificidad en la órbita laboral y lo que ocurre fuera de ellas puede aportar a alcanzar una mirada más compleja del proceso histórico y a rescatar diálogos posibles que de otra manera quedarían opacados.

Así, las voces provenientes del mundo académico y experto sobre accidentes laborales proporcionaron evidencias para comprender que la doctrina del "riesgo profesional" se imponía como principio jurídico a la hora de resolver los litigios en casos de infortunios en el trabajo. Sin embargo, ese recorrido no siguió una trayectoria lineal sino que presentó vaivenes, ya que los fallos dictaminados por los jueces no se amalgamaron en la premisa del "riesgo profesional" y, en ciertos casos, la culpa como determinante de la responsabilidad indemnizatoria o no del patrón siguió siendo punto de referencia aún a mediados de la década de 1910. La ley nº 9688 fue, en opinión de los abogados reclutados en las filas del DNT, el mejor producto posible para arbitrar los casos de accidentes. No obstante, desde 1915 en adelante las críticas a las imprecisiones que presentaban ciertos conceptos de la ley cobraron vigencia entre quienes aspiraban a doctorarse en jurisprudencia y en los planteos parlamentarios que sugerían reformas a la legislación recientemente sancionada. El precepto del "riesgo profesional" se aplicaba como elemento rector en la norma, pero las imperfecciones que ésta aún presentaba eran más bien un obstáculo para una interpretación unívoca de sus alcances y limitaciones. Los jueces, de esa manera, siguieron teniendo un margen de maniobrabilidad a la hora de sustentar sus fallos, aunque más estrecho que en los tiempos que precedieron a la ley $n^{\circ} 9688$. Pero esos intersticios que dejaba la norma en algunos de sus aspectos se completaban con precisiones que limitaban los alcances de la indemnización que podrían llegar a afrontar los empresarios. Si atender a las problemáticas que traía aparejada la cuestión social estaba entre las premisas de la legislación obrera de la época, en la ley de accidentes la preocupación del mundo jurídico estribaba fundamentalmente en reducir al mínimo posible los riesgos e imprevistos que una sanción legislativa podría causar a la patronal. 


\section{REFERENCIAS}

Aragoneses, A. (2015). Crisis del derecho privado y legislación especial en Francia y en Argentina. En M. R. Polotto, T. Keiser y T. Duve (Eds.), Derecho privado y modernización. América Latina y Europa en la primera mitad del siglo XX (pp. 119-151). Frankfurt am Main: Max Planck Institute for European Legal History.

Bielsa, R. (1919). La culpa en materia de accidentes del trabajo. Su estudio y crítica en la Ley argentina (aspecto jurídico de la cuestión). Buenos Aires: J. Lajouane \& Cia. Editores-Librería Nacional.

Bonaparte, L. D. (1917). Responsabilidad de los patrones por los accidentes del trabajo. (Tesis presentada a la Facultad de Derecho y Ciencias Sociales de la Universidad de Santa Fe). [Sin datos de editorial].

Bourdieu, P. (2000 [1990]). Las condiciones sociales de la circulación de ideas. En P. Bourdieu. Intelectuales, politica ypoder (pp. 159-170). Buenos Aires: Eudeba.

Buchbinder, P. (2005). Historia de las universidades argentinas. Buenos Aires: Sudamericana.

Chazarreta, J. [S. f.] La culpa en materia de accidentes del trabajo. Su estudio en el derecho argentino. (Tesis presentada para optar al grado de doctor en jurisprudencia) [Sin datos de editorial].

Das, V. y Poole, D. (2008). El Estado y sus márgenes. Etnografías comparadas. Cuadernos de Antropología Social, 27, pp. 19-52.

Dezalay, Y. y Garth, B. (2002). The Internationalization of Palace Wars: Lawyers, Economists, and the Contest to Transform Latin American States. Chicago/Londres: Chicago University Press.

Díaz, J. C. (1918). La culpa en materia de accidentes de trabajo. [Sin datos de editorial].

Figueroa Gacitúa, G. (1918). La culpa en materia de accidentes del trabajo. Su estudio en el derecho argentino. [Sin datos de editorial].

Frederic, S., Graciano, O. y Soprano, G. (2010). Profesión, Estado y Política. Estudios sobre la formación académica y configuración profesional en la Argentina. En S. Frederic, O. Graciano y G. Soprano (Coords.). El Estado argentino y las profesiones liberales, académicas y armadas (pp. 13-46). Rosario: Prohistoria Ediciones.

Gorlero Pizarro, E. (1907). Accidentes de trabajo. (Tesis presentada para optar al grado de doctor en jurisprudencia. UBA), Buenos Aires. [Sin datos de editorial].

Haidar, V. (2008). Trabajadores en riesgo. Una sociología histórica de la biopolitica de la población asalariada en Argentina (1890-1915). Buenos Aires: Prometeo.

Halperín Donghi, T. (2013 [1962]). Historia de la Universidad de Buenos Aires. Buenos Aires: Eudeba.

Hardoy, E. (1901). La responsabilidad civil y los accidentes del trabajo. (Tesis presentada para optar al grado de doctor en jurisprudencia. UBA). Buenos Aires: Imprenta de M. Biedma e hijo.

Levaggi, A. (2006). Historia del Derecho Argentino. Iushistoria, 3. Recuperado de http://p3.usal.edu.ar/index.php/ iushistoria/article/view/1617/2050

Lobato, M. Z. y Suriano, J. (2014). Trabajo, cuestión social e intervención social. En Lobato, M. Z. y Suriano, J. (Comps.). La Sociedad del Trabajo. Las instituciones laborales en la Argentina (1900-1955) (pp. 9-56). Buenos Aires: Edhasa.

Marcó del Pont, R. (1898). Responsabilidad en los accidentes del trabajo. (Tesis presentada para optar al grado de doctor en jurisprudencia. UBA). Buenos Aires: Imprenta de M. Biedma e hijo.

Migdal, J. (2001). Una antropología del Estado. Luchas por la dominación. En J. Migdal. Estados débiles, Estadosfuertes (pp. 123-178). México: FCE.

Mitchell, T. (2015). Sociedad, economía y el efecto del estado. En P. Abrams, A. Gupta y T. Mitchell (Eds.), Antropología del Estado (pp. 145-187). México: FCE.

Morresi, S. y Vommaro, G. (2011). Los expertos como dominio de estudio socio-político. En S. Morresi y G. Vommaro (Comps.). Saber lo que se hace. Expertos y politica en Argentina (pp. 9-41). Buenos Aires: Universidad Nacional de General Sarmiento-Prometeo Libros.

Pelento, P. (1918). La culpa en materia de accidentes del trabajo. Análisis y crítica de la ley argentina. (Tesis presentada para optar al grado de doctor en jurisprudencia). [Sin datos de editorial]. 
Plotkin, M. y Zimmermann, E. (2012). Introducción. Saberes de Estado en la Argentina, siglos XIX y XX. En M. Plotkin y E. Zimmermann (Comps.). Los saberes del Estado (pp. 9-28). Buenos Aires: Edhasa.

Rabinbach, A. (1996). Social Knowledge, Social Risk, and the Politics of Industrial Accidents in Germany and France. En D. Rueschemeyer y T. Skocpol (Comps.), States, Social Knowledge, and the Origins of Modern Social Policies (pp. 48-89). New Jersey: Princeton, University Press.

Ramacciotti, K. (2014a). ¿Soldados del trabajo o ciudadanos? La ley de accidentes de trabajo en la Argentina, 1915-1955. En: M. Z. Lobato y J. Suriano (Comps.). La Sociedad del Trabajo. Las instituciones laborales en la Argentina (1900-1955) (pp. 293-317). Buenos Aires: Edhasa.

Ramacciotti, K. (2014b). Influencias internacionales sobre la gestión de los accidentes de trabajo en Argentina. Primera mitad del siglo XX.e-l@tina, 12(48). Recuperado de http://publicaciones.sociales.uba.ar/index.php/elatina

Ruzo, A. (1906). Legislación obrera. (Tesis presentada para optar al grado de doctor en jurisprudencia. UBA). Buenos Aires: Imprenta de M. Biedma e hijo.

Salvatierra, D. (1905). Accidentes de trabajo. (Tesis presentada para optar al grado de doctor en jurisprudencia. UBA). Buenos Aires: Las ciencias.

Schjolden, L. (2009). Sentencing the Social Question: Court-Made Labour Law in Cases of Occupational Accidents in Argentina, 1900-1915. Journal of Latin American Studies, 41(1), 91-120.

Suriano, J. (2000). Introducción: una aproximación a la definición de la cuestión social en Argentina. En J. Suriano (Comp.), La cuestión social en Argentina, 1870-1943 (pp. 1-29). Buenos Aires: La Colmena.

Suriano, J. (2015). El mundo como un taller de observación. La creación del Departamento Nacional del trabajo y las influencias internacionales. Revista de Indias. LXXIII(257), 107-130. Recuperado de http://revistadeindias.rev istas.csic.es/index.php/revistadeindias/article/view/919

Unsain, A. (1915). Manual de la Legislación Obrera Argentina. Buenos Aires: Compañía Sud Americana de Billetes Banco.

Unsain, A. (1916) Leyes obreras argentinas. Recopiladas y anotadas con los decretos que las reglamentan. Buenos Aires: Imp. Argentina Jacobo Peuser.

Unsain, A. (1917). Accidentes del Trabajo. Exposición y comentarios a la Ley $N^{\circ} 9.688$ y sus decretos reglamentarios. Buenos Aires: Editorial Gotelli y Peralta.

Zimmermann, E. (1995). Los liberales reformistas. La cuestión social en la Argentina, 1890-1916. Buenos Aires: Sudamericana.

Zimmermann, E. (2013). “Un espíritu nuevo”: la cuestión social y el Derecho en la Argentina (1890-1930). Revista de Indias, LXXIII(257), 81-106. Recuperado de http://revistadeindias.revistas.csic.es/index.php/revistadeindi as/article/view/918

\section{Notas}

1 El autor agradece las sugerencias y observaciones realizadas por quienes evaluaron anónimamente el artículo.

2 Ricardo Marcó del Pont cumplió funciones en el ámbito público y también en el privado. Entre ellas se destacaron su rol de Secretario en la Facultad de Ciencias Jurídicas y Sociales de la Universidad Nacional de La Plata y su lugar de abogado representante de la empresa naviera Mihanovich.

3 Una interpretación interesante al tema de los accidentes de trabajo en Alemania y Francia, en clave comparativa, puede encontrarse en Anson Rabinbach. Rabinbach (1996, pp. 48-89) destacó cómo, por medio de la gestión de los accidentes de trabajo, lo que estaba poniéndose en juego era la intromisión estatal en la regulación de las relaciones laborales. A su vez, el autor reconstruye la forma en que la doctrina de la "culpa" fue dando paso a la doctrina del "riesgo profesional" e indaga hasta dónde fue sustentable la afirmación, común también al caso argentino, que veía que una mayor tecnificación de los procesos productivos implicaba un aumento de los accidentes.

4 Emilio Hardoy se destacó por cumplir funciones públicas como Director General de los puertos de Buenos Aires y La Plata.

5 Bourdieu (2000 [1990]) ha señalado el uso utilitarista que se otorga a pensadores foráneos para argumentar una posición en un espacio nacional al afirmar: "Los autores extranjeros son frecuentemente objeto de usos muy instrumentalistas; son 
frecuentemente utilizados para causas que quizás ellos mismos reprobarían o recusarían en su propio país. Uno podrá, por ejemplo, servirse de un extranjero para abatir a nacionales" (p. 163).

6 La vaguedad del Código Civil para regular cuestiones del mundo laboral quedaba demostrada en su artículo 1109, según el cual "todo el que ejecute un hecho que por su culpa o negligencia ocasione un daño a otro, está obligado a la reparación del perjuicio", y que servía de instrumento a los jueces para resolución de los conflictos en casos de accidentes.

7 La sentencia de Quesada sostenía que "el obrero no tiene por qué entrar a alegar si ha habido o no culpa, dolo o negligencia por parte del patrono o de su delegado: le basta alegar y probar el daño sufrido y que él [Falta intercalar una "a"] le ha ocurrido en el trabajo o en ocasión del trabajo; es el patrono quien únicamente puede descargarse en el todo o en parte de su responsabilidad, alegando la compensación de la culpa del obrero que exceda de lo inherente al oficio, arte o profesión, puesto que responde hasta del caso fortuito o de fuerza mayor". Citado en Levaggi (2006, pp. 59-60).

8 Boletín del Departamento Nacional del Trabajo (en adelante BDNT), n 1, 30 de junio de 1907, p. 115.

9 Alejandro Ruzo fue docente en la cátedra de finanzas de la FDyCS-UBA, que conjugó con su especificidad sobre cuestiones laborales, lo que lo dotó de avales para ingresar al DNT desde su creación en 1907, y años más tarde ocupar la dirección de la Sección de Estudios Legales y Estadísticos de dicha entidad. La trayectoria de Ruzo en el ámbito político se complementó cuando en 1925 fue elegido senador por la provincia de Catamarca, cargo que perdió tras el golpe militar de 1930.

10 Pablo Storni estudió las clases obreras en la ciudad de Buenos Aires, como colaboración del proyecto legislativo que Joaquín V. González presentó en 1904. En 1912, luego de sancionada la ley orgánica del DNT, quedó a cargo de la sección de Inspección.

11 El papel de los seguros contra accidentes de trabajo fue considerado un método eficaz para proporcionar una cobertura que garantizara un resarcimiento económico en favor de los trabajadores accidentados. Sin embargo, el debate al respecto circundó en torno a si dichos seguros debían ser una obligación para los patrones o, por el contrario, o si debían tener ellos la potestad de optar por su contratación; y en caso de no hacerlo, asumir los riesgos que tal decisión traía aparejada.

12 Alejandro Unsain estuvo vinculado al estudio de las relaciones laborales a partir de su actividad docente en las Universidades de Buenos Aires y de La Plata, y entre 1920 y 1922 fue presidente del DNT. Desde allí influiría en la política laboral trazada por el radicalismo promocionando la implementación de un Código de Trabajo.

13 Ruzo (1906, p. 160) quizás presentó uno de los primeros análisis que se refirieron a cómo se pensaban los accidentes en América, cuando citó al Dr. David Matto, médico catedrático de la Universidad Nacional de San Marcos de Lima, quien se dedicó a psiquiatría y bacteriología, y había opinado que un herido en un accidente ferroviario había perdido la razón y ese hecho lo convertía en un accidentado laboral.

14 Pedro Pelento (p. 58) sostuvo que la ley de accidentes era de las mejores del mundo.

15 Para Figueroa Gacitúa (1918), pasa casi inadvertida la sanción de la ley n 9688 y la extensión temporal de su análisis alcanza las vísperas de 1915.

$16 \mathrm{Al}$ respecto, es sugerente la propuesta de Migdal: "El primer paso para entender las diferentes direcciones en que jalan los componentes del Estado es identificar las fuerzas que constituyen los diversos ambientes en los que se mueven los funcionarios del Estado. Sólo entonces podrá un investigador comenzar a indagar el peso de estas fuerzas para diferentes partes del Estado en circunstancias específicas" (Migdal, 2001, p. 152). 